\title{
Functional Level During the First Year After Moderate and Severe Traumatic Brain Injury: Course and Predictors of Outcome
}

\author{
Maria Sandhaug ${ }^{\mathrm{a}, \mathrm{b}, \mathrm{e}}$, Nada Andelic ${ }^{\mathrm{c}}$, Svein A Berntsen ${ }^{\mathrm{b}}$, Stephen Seiler ${ }^{\mathrm{a}}$, Aase Mygland ${ }^{\mathrm{a}, \mathrm{b}, \mathrm{d}}$
}

\begin{abstract}
Background: The objective of this study was to describe the functional level during the first year after moderate and severe traumatic brain injury (TBI), and to evaluate the predictive impact of preinjury and injury-related factors.
\end{abstract}

Methods: A cohort of 65 patients with moderate $(\mathrm{N}=21)$ or severe $(\mathrm{N}=44)$ TBI were examined with FIM (Functional Independence Measure) at admission and discharge from the rehabilitation clinic (on average two months after injury) and at 12 months, and with GOSE (Glasgow Outcome Scale Extended) at 12 months after injury. Possible predictors were analyzed in a regression model using FIM total score at 12 months as outcome.

Results: All mean FIM scores improved significantly from injury to discharge from sub-acute rehabilitation. In the later period from discharge to 12 months after injury, the mean FIM motor score improved in severe TBI but not in moderate TBI patients. The mean FIM cognitive scores did not improve in any of the groups. At 12 months, 95\% with moderate TBI had a FIM score from 109 - 126 (functionally independent) compared to $74 \%$ with severe TBI. Functional global outcome as assessed by GOSE was "good recovery" in 52\% with moderate TBI versus $33 \%$ in severe TBI, "moderate disability" in $33 \%$ with moderate TBI versus $31 \%$ in severe TBI, and "severe disability" in $14 \%$ with moderate TBI versus $36 \%$ in severe TBI. Predictors such as PTA duration $(B=-0.209)$, GCS

Manuscript accepted for publication May 27, 2011

${ }^{a}$ Faculty of Health and Sports, Agder University, Kristiansand, Norway ${ }^{\mathrm{b}}$ Clinic for Rehabilitation, Sorlandet Hospital, Kristiansand, Norway

${ }^{\mathrm{c}}$ Department of Physical Medicine and rehabilitation, Oslo University Hospital, Ulleval, Norway

${ }^{\mathrm{d}}$ Institute of Clinical Medicine, University of Bergen, Bergen, Norway ${ }^{\mathrm{e} C o r r e s p o n d i n g ~ a u t h o r: ~ M a r i a ~ S a n d h a u g, ~ F a c u l t y ~ o f ~ H e a l t h ~ a n d ~ S p o r t s, ~}$ Agder University, Service box 422, 4604 Kristiansand, Norway.

Email: maria.sandhaug@uia.no

doi:10.4021/jnr20w admission rehabilitation $(\mathrm{B}=5.058)$ and LOS rehabilitation $(\mathrm{B}=$ 0.458 ) explained $47 \%$ of the FIM variance 12 months post injury.

Conclusions: The greatest improvement after moderate and severe TBI was in the sub-acute phase during the stay in a specialized rehabilitation unit. Residual disability was reported in $47 \%$ of moderate TBI patients as measured by GOSE at 12 months post injury indicating the importance of post-acute rehabilitation for these patients. Longer stays at the rehabilitation unit, a short PTA period and a high GCS score at admission to rehabilitation were positive predictors of functional level (FIM) at 12 months follow-up demonstrating that these factors are common predictors of early and late TBI phases.

Keywords: Level of function; Global outcome; Rehabilitation; Traumatic brain injury

\section{Introduction}

Functional outcome prediction after traumatic brain injury (TBI) is important for rehabilitation professionals to direct treatment efforts and for patients and families who need information about long-term implications [1]. Defining and evaluating predictors that influence functional outcome has therefore been a goal of clinical treatment within rehabilitation medicine [2]. Predictive modelling is however difficult due to the numerous complex clinical elements that occur and interplay after TBI [2].

Several factors are reported to correlate with recovery and functional long-term outcome: duration of post-traumatic amnesia (PTA) [1], Glasgow Coma Scale (GCS) score [3], length of coma (LOC) [3], age, race and violent injury [1]. PTA seems to be the strongest predictor of outcome [1,3].

Prediction of long-term functional outcome after TBI is still uncertain, especially among the moderately injured, since most studies report on outcome after severe TBI [1-3]. In a previous study of functional level during sub-acute rehabilitation, we found that a considerable portion of patients with moderate TBI had residual disability at discharge from sub-acute rehabilitation [4]. In the present study, we have followed a patient cohort with moderate and severe TBI for 
12 months after injury. The reason why we conducted this study was limited investigation in this field in our region. In general, there are several recently published retrospective studies that comprise long-term recovery after moderate and severe TBI [5-7]. But prospective studies on functional recovery and outcome are limited $[8,9]$. Studies from different countries are required to provide "better understanding of regional, national and international differences and needs in the area of brain injury rehabilitation" [10].

The purpose of this study was to describe the course of functional recovery during the first 12 months after moderate and severe TBI as measured by Functional Independence Measure (FIM), and to examine the global outcome at 12 months as evaluated by Glasgow Outcome Scale Extended (GOSE). We also wanted to examine the influence of various factors as predictors on FIM outcome at 12 months.

\section{Materials and Methods}

\section{Subjects}

We considered for inclusion consecutive patients with TBI admitted directly from acute care hospitals to the Clinic for Rehabilitation in Kristiansand in the period from December 2005 to November 2008.

During the autumn 2005, we gave lessons about classification of TBI to doctors at Sorlandet Hospital and encouraged them to transfer all patients with moderate and severe TBI to rehabilitation. Exclusion criteria were age $\leq 16$ years, TBI classified as mild (as defined by the American Congress of Rehabilitation Medicine (ACRM)) [11], vegetative state (no response indicative of consciousness during the rehabilitation stay), and serious co-morbidities which would have interfered with assessment of TBI related impairments such as associated spinal cord injuries, previously diagnosed severe psychological disorders, and/or substance abuse. Vegetative state was listed as an exclusion criterion since the Regional Committee for Medical Research Ethics did not approve written consent certified by a close relative if the patient was disabled from signing. Patients were admitted from Sorlandet Hospital (the regional acute hospital with three locations in Southern Norway) where they, after intensive care, had acute rehabilitation in either a Neurology department (31 patients) or a Surgery department (18 patients). Three TBI patients were admitted directly from a Level 1 trauma center at Oslo University Hospital, Ulleval.

We also included 13 patients from a cooperation project treated in a specific rehabilitation unit at Oslo University Hospital, Ulleval (a Level I trauma center). This project is a similar follow-up study of TBI patients from Eastern Norway where the same exclusion criteria were applied. Five of the 13 included patients had moderate TBI. Written consent was obtained from all participants. The Regional Commit- tee for Medical Research Ethics approved the study. Our research was approved by the committee on research ethics at the institution in which the study was conducted and in accordance with the Declaration of the World Medical Association.

\section{Sub-acute rehabilitation}

All patients received interdisciplinary brain injury rehabilitation given by a specialized rehabilitation team: physiatrist, nurse, physiotherapist, occupational therapist, speech therapist, psychologist, neuropsychologist and social worker. Their focus was to optimize recovery of functional independence and educate the patients and their families regarding TBI consequences and their management. In general, discharge from rehabilitation was decided when patients reached a functional plateau of clinical improvement or achieved their functional goals.

\section{Post-acute rehabilitation}

A specialized brain injury rehabilitation team from our Clinic for Rehabilitation provided assistance and education to patients and their rehabilitation programmes at home and in other institutional settings. Home visits and assessments were made three months after discharge from our Clinic for rehabilitation. Fifty-two patients received this form of postacute rehabilitation.

\section{Follow-up}

Home visits and assessments of FIM and GOSE scores were made 12 months after injury. If requested by the patients or considered necessary, regular contact by telephone and home visits with our specialized rehabilitation team was scheduled. Face-to-face interviews were administrated for 13 patients included from the Level 1 trauma center.

\section{Independent variables}

The following baseline information was recorded in all patients: gender, age, marital status (alone/live with), education $(<12 / \geq 12$ years), previous head injuries (yes/no), place of acute care (neurology department/surgery department/ level 1 trauma center), injury mechanism (traffic accidents, falling, violence/sports/other), injury localization extracted from the clinical description of the head CT scan (frontal/ non-frontal region) [12], injury severity (severe/moderate), other injuries (none $/ \geq 1$ ), complications (none $/ \geq 1$ ), alcohol/ drug influence at time of injury (yes/no), length of stay in acute hospital (LOS acute), length of stay in rehabilitation hospital (LOS rehab), PTA duration, Glasgow Coma Scale (GCS) at admission to acute hospitalization (GCS acute), and GCS at admission to the rehabilitation unit (GCS rehab). 
Table 1. Pre-Analyses of Patient Characteristics in Relation to FIM 12 Months After Injury

\begin{tabular}{|c|c|c|c|c|}
\hline Predictor & $\mathbf{N}(\%)$ & FIM 12 months (SD) & Corr* & P-value \\
\hline \multicolumn{5}{|l|}{ Place of acute care } \\
\hline Regional hospital & $48(76)$ & $113( \pm 26)$ & & 0.229 \\
\hline Level 1 trauma center & $15(24)$ & $119( \pm 21)$ & & \\
\hline Rehab team (yes/no) & $50(79) / 13(21)$ & $112( \pm 28) / 125( \pm 4)$ & & 0.101 \\
\hline Gender $\mathrm{M} / \mathrm{F}$ & $48(76) / 15(24)$ & $115( \pm 23) / 111( \pm 32)$ & & 0.280 \\
\hline Age & $63(100)$ & & -0.072 & 0.575 \\
\hline Civil status (alone/live with) & $30(48) / 32(52)$ & $117( \pm 19) / 112( \pm 30)$ & & 0.670 \\
\hline Education $(<12 / \geq 12)$ & $24(52) / 22(48)$ & $116( \pm 25) / 122( \pm 17)$ & & 0.943 \\
\hline Alcohol/drug (yes/no) & $17(16) / 43(26)$ & $120( \pm 16) / 113( \pm 26)$ & & 0.140 \\
\hline Other injuries (none/ $\geq 1$ ) & $38(60) / 25(40)$ & $121( \pm 16) / 110( \pm 29)$ & & 0.067 \\
\hline Complications (none/ $\geq 1$ ) & $15(29) / 37(71)$ & $117( \pm 19) / 106( \pm 36)$ & & 0.015 \\
\hline \multicolumn{5}{|l|}{ Injury severity } \\
\hline Moderate TBI & $21(33)$ & $123( \pm 13)$ & & $<0.001$ \\
\hline Severe TBI & $42(66)$ & $110( \pm 29)$ & & \\
\hline \multicolumn{5}{|l|}{ Injury mechanism } \\
\hline Traffic accidents & $32(51)$ & $114( \pm 28)$ & & 0.424 \\
\hline Falling & $23(37)$ & $112( \pm 25)$ & & \\
\hline Violence, sports, other & $8(13)$ & $126( \pm 1)$ & & \\
\hline \multicolumn{5}{|l|}{ Injury localization } \\
\hline Frontal & $17(28)$ & $115( \pm 25)$ & & 0.699 \\
\hline Non-frontal & $43(72)$ & $116( \pm 23)$ & & \\
\hline PTA duration (days) & $63(100)$ & & -0.512 & $<0.001$ \\
\hline LOS acute & $63(100)$ & & -0.357 & $<0.004$ \\
\hline LOS rehab & $63(100)$ & & -0.397 & $<0.001$ \\
\hline GCS acute & $62(100)$ & & -0.377 & $<0.002$ \\
\hline GCS rehab & $63(100)$ & & 0.536 & $<0.001$ \\
\hline FIM adm & $63(100)$ & & 0.588 & $<0.001$ \\
\hline FIM disch & $63(100)$ & & 0.708 & $<0.001$ \\
\hline
\end{tabular}

Numbers are given as mean values if not otherwise indicated. M/F: Male/Female; PTA: Post-Traumatic Amnesia; LOS acute: Length of Stay acute hospitalization; LOS rehab: Length of Stay in rehabilitation hospital; GCS acute: Glasgow Coma Scale acute hospitalization; GCS rehab: Glasgow Coma Scale in rehabilitation hospital; FIM Adm/Disch: Functional Independence Measure Admission/Discharge. * Spearman's Rank Order Correlation. N = 63 due to missing FIM values in 2 out of 65 subjects. Missing 17 responses in the education predictor. Missing 11 responses in the complication predictor. 
We included patients with moderate and severe TBI and excluded those with mild TBI. Mild TBI was defined by an initial GCS of 13 - 15, change in mental status without loss of consciousness (LOC), or LOC up to 30 minutes and PTA up to 24 hours, as suggested by ACRM [11]. Moderate TBI was defined by GCS of 9 - 12 and LOC more than 30 minutes, but less than 6 hours. Patients with clinical features of mild TBI, but who had traumatic CT pathology were upgraded to moderate TBI. Severe TBI was defined by GCS of $\leq 8$ and LOC more than 6 hours. After collecting data we upgraded the severity from mild to moderate in 6 patients with CT pathology and 4 patients from moderate to severe where extended LOC suggested a more severe injury than indicated by the GCS. We were not able to obtain GCS score in one of the patients.

PTA duration was defined as the interval in days between injury and obtaining a "normal" score on the Galveston Orientation and Amnesia Test (GOAT) [13]. The GOAT 10-item scale, evaluates the major spheres of orientation (time, place, and person) and the ability of the patient to recall personal information and facts about recent events following injury. As such the GOAT assesses temporal orientation concerning the day of week, day of month, year, and time of day. A total score of 76 - 100 indicates that a person is oriented, while a total score of 65 or less indicates impaired orientation [13]. In-between scores are considered borderline. GOAT assessment was performed by a hospital psychologist.

\section{Outcome variables}

FIM was used to measure functional levels at admission and discharge from sub-acute rehabilitation as well as 12 months after injury. The FIM is an 18-item rating scale assessing self-care, bowel and bladder management, mobility, communication, cognition, and psychosocial adjustment [14]. Each item is rated on a scale from 1 (total assistance) to 7 (complete independence) [15]. The FIM consists of two subscales, FIM Motor (FIM-M) and FIM Cognitive (FIM-
COG). The FIM-M consists of 13 items of motor function and movement (score range 13 - 91) and the FIM-COG 5 items regard the processing of information, interaction with others, and communication (score range 5 - 35), giving a total FIM score range of 18 to 126 . A total FIM score (sum of FIM-M and FIM-COG) of $\leq 108$ indicates limitation in activities and need for assistance from another person while scores of 109 - 126 indicate functional independence. The FIM has previously been shown to be both valid and reliable for measuring functional outcome after TBI [16]. The FIM scoring was performed by a certified interdisciplinary team (physician, nurse, occupational therapist, and physiotherapist) during the first week after admission and the last week before discharge and at 12 months follow-up. For this study, differences of 2 or more FIM units were considered to be clinically important [17].

The GOSE measures a combination of neurological functioning and dependence on others with eight outcome categories ranked 1 to 8 : score $8=\operatorname{good}$ recovery, score $7=$ good recovery with minor physical or mental deficits, score $6=$ moderate disability and return to previous work with some adjustments, score $5=$ moderate disability and work at a lower level of performance, score $4=$ severe disability and for some activities dependent upon others, score $3=$ severe disability and completely dependent on others, score 2 $=$ vegetative state, score $1=$ death [18]. The GOSE has been reported to be a good method for assessment of upper range of outcome, and sensitive for detection of good recovery or moderate disability in moderate TBI [19]. The GOSE scoring was performed as face-to-face interviews by a certified interdisciplinary team (physician, nurse, occupational therapist, and physiotherapist) 12 months after injury.

\section{Statistical analysis}

FIM variables from three assessment periods in moderate and severe TBI groups were compared statistically using Mixed Model Analyses and Friedman test for comparison

Table 2. Results of Multiple Regression Analysis With FIM

\begin{tabular}{lll}
\hline Variable & B Coefficient $(\mathbf{9 5 \%}$ CI) & P-value \\
\hline Constant & $32.195(-7.673-72.062)$ & 0.111 \\
Gender & $-8.013(-19.313-3.286)$ & 0.161 \\
PTA duration & $-0.211(-0.391--0.031)$ & 0.022 \\
LOS rehab & $0.419(0.059-0.778)$ & 0.023 \\
GCS rehab & $5.234(2.476-7.993)$ & $<0.001$ \\
FIM adm & $0.180(-0.082-0.441)$ & 0.174 \\
\hline
\end{tabular}

Adjusted R Square for the model: 0.474 .

${ }^{*}$ Number of patients, $\mathrm{N}=63$. 
Table 3. Functional Measures at Admission, Discharge and 12 Months After Moderate or Severe TBI

\begin{tabular}{|c|c|c|c|c|}
\hline & Adm rehab. $( \pm$ SD $)$ & Disch rehab. $( \pm$ SD $)$ & 12 months $( \pm \mathrm{SD})$ & P-value \\
\hline \multicolumn{5}{|c|}{ Moderate TBI $(\mathrm{n}=21)$} \\
\hline FIM total & $109( \pm 21)$ & $124( \pm 3)$ & $123( \pm 13)$ & $\begin{array}{l}0.005^{* *} \\
0.009^{* * *} \\
1.000^{* * * *} \\
0.018^{* *}\end{array}$ \\
\hline FIM-M & $82( \pm 15)$ & $91( \pm 9)$ & $89( \pm 9)$ & $\begin{array}{l}0.083 * * * \\
1.000 * * * * \\
<0.001 * *\end{array}$ \\
\hline FIM-COG & $27( \pm 8)$ & $33( \pm 3)$ & $34( \pm 4)$ & $\begin{array}{l}<0.001 * * * \\
1.000 * * * *\end{array}$ \\
\hline \multicolumn{5}{|c|}{ Severe TBI $\left(\mathrm{n}=44^{*}\right)$} \\
\hline FIM total & $81( \pm 5)$ & $101( \pm 5)$ & $113( \pm 29)$ & $\begin{array}{l}<0.001^{* *} \\
<0.001^{* * *} \\
0.005^{* * * *} \\
<0.001^{* *}\end{array}$ \\
\hline FIM-M & $60( \pm 4)$ & $75( \pm 4)$ & $83( \pm 4)$ & $\begin{array}{l}<0.001 * * * \\
0.050 * * * *\end{array}$ \\
\hline FIM-COG & $22( \pm 2)$ & $28( \pm 2)$ & $29( \pm 2)$ & $\begin{array}{l}0.005^{* *} \\
<0.001^{* * *} \\
1.000^{* * * *}\end{array}$ \\
\hline
\end{tabular}

Values are given as mean if not otherwise specified. FIM total: Functional Independence Measure total score (best score 126); FIM-M: FIM Motor sub-score (best score 91); FIM-COG: Cognitive sub-score (best score 35). P-values are given with post hoc Bonferroni correction. ${ }^{*} \mathrm{~N}=42$ at 12 months follow-up. ${ }^{* *} \mathrm{P}$-value between adm rehab and disch rehab. ${ }^{* *} \mathrm{P}$-value between adm rehab and 12 months follow-up. ${ }^{* * *} \mathrm{P}$-value between disch rehab and 12 months follow-up.

of individual changes within the severity groups from rehabilitation admission to one year after injury [20]. GOSE results in both severity groups were compared statistically using Chi-square.

The dependent variable in our regression analysis was FIM 12 months after injury. The patient characteristics considered for use as independent variables are shown in Table 1. These independent variables were compared to FIM 12 months after injury by using Spearman's Rank Order Correlation, Kruskall-Wallis Test, Mann-Whitney U Test, Independent Samples T-test or ANOVA. In the pre-analyses subjects were divided into two groups of either acute treatment at a general surgery department (48 subjects) or a neurosurgery intensive care department (15 subjects). FIM score at admission to sub-acute rehabilitation was included as a covariate to adjust for the baseline level. Independent variables of clinical importance or with $\mathrm{P}$ values $<0.05$ in pre-analyses were then entered into a multiple linear regression model to quantify their predictive impact on FIM at discharge. Initially, 11 variables of clinical interest or $\mathrm{P}<0.05$ were entered in the multiple regression analysis (gender, age, drug/alcohol, injury severity, PTA duration, LOS acute, LOS rehab, GCS acute, GCS rehab, FIM adm, other injuries). Complications were not included as a predictor because of 11 missing responses. Due to a conservative approach of allowing one predictor for every 10 participants $(n=62)$, the 6 variables with lowest P-values were re-entered (Table 2).
Variables that were strongly correlated to another variable $(\mathrm{r}$ $>0.7$ ) were as a rule excluded from analysis in the regression model. In the model, all variables were controlled for collinearity (VIF), distribution of the residuals for normality and influential data points were examined using Cook's distance. Tests for multicollinearity and bias were negative. None of the variables were less than five or greater than 10 , indicating no presence of multicollinearity or bias. All data were analysed using SPSS version 15.0 and results were considered significant at the $\mathrm{P}<0.05$ level.

\section{Results}

Sixty-five patients (21 with moderate and 44 with severe TBI) were included initially. One patient was excluded because of vegetative state. No patients were excluded because of psychological disorders and/or substance abuse, but 17 patients were influenced by alcohol/drugs at the time of injury. In the FIM and GOSE analyses at 12 months the number of subjects was reduced to 63 due to missing values in two patients.

\section{Demographics and severity of TBI}

Our 65 patients had mean age $41 \pm 18$ years, 50 (77\%) were males and $15(23 \%)$ females. Patients with moderate and se- 
Injury severity: Mod TBI (left) vs. Sev TBI (right)

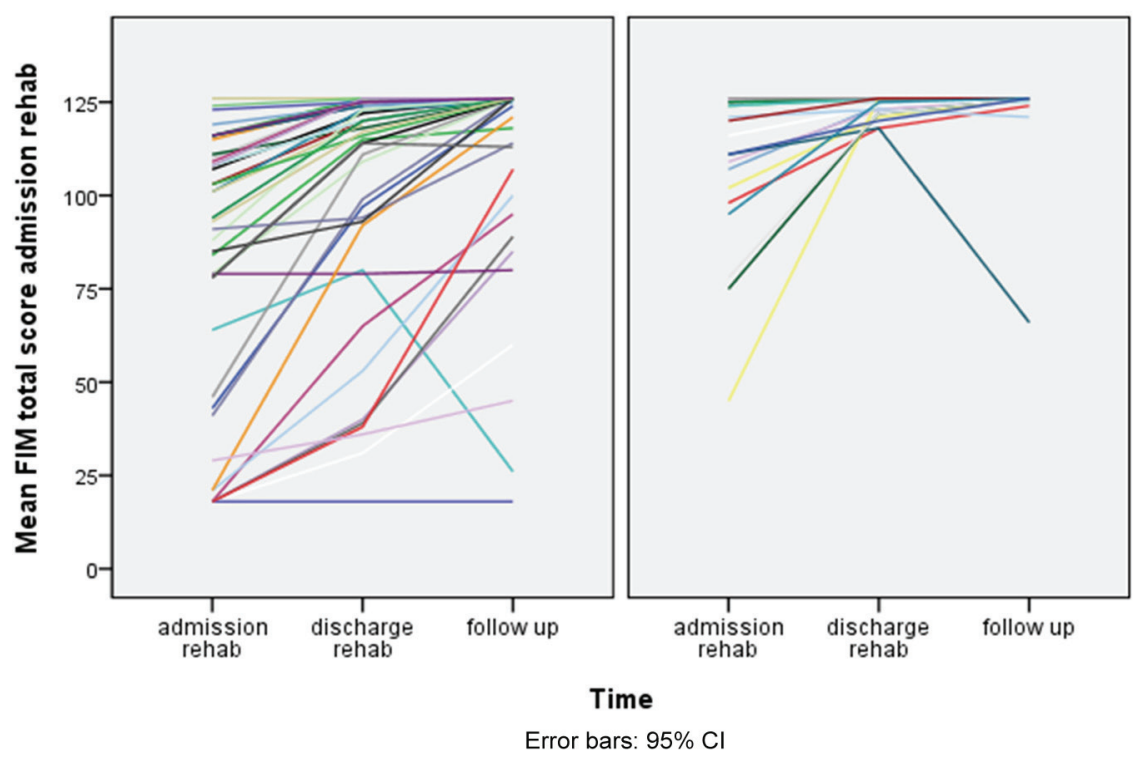

Figure 1. Individual FIM scores in moderate and severe TBI patients.

vere TBI were similar regarding civil status $(\mathrm{P}=0.328)$ and education ( $\mathrm{P}=0.585)$. Falls accounted for $48 \%$ of the injuries in the moderate TBI group as compared to $34 \%$ in severe TBI $(\mathrm{P}=0.465)$. Traffic accidents accounted for $38 \%$ versus $54 \%(\mathrm{P}=0.465)$, and sports and violence for $14 \%$ versus $11 \%(\mathrm{P}=0.465)$, respectively. The types of intracranial injuries were subarachnoid bleedings $(20 \%$ in moderate TBI versus $32 \%$ in severe TBI, $\mathrm{P}=0.421)$, contusions ( $15 \%$ versus $46 \%$ respectively, $\mathrm{P}=0.187)$, subdural hematoma $(14 \%$ versus $32 \%$ respectively, $\mathrm{P}=0.919)$, intracranial bleedings (11\% versus $14 \%, \mathrm{P}=0.413)$, edema ( $8 \%$ versus $12 \%, \mathrm{P}=$ $0.697)$, epidural hematoma ( $5 \%$ versus $17 \%, \mathrm{P}=0.509)$, and diffuse axonal injury ( 0 versus $11 \%, \mathrm{P}=0.035)$. At discharge from the rehabilitation clinic, 5 percent of patients with moderate TBI were still in PTA phase versus $16 \%$ in those with severe TBI $(\mathrm{P}=0.020)$. Mean PTA duration in days was $11 \pm$ 14 versus $44 \pm 44(\mathrm{P}<0.001)$.

\section{Length of stays and discharge place}

Transfer to the specialized rehabilitation unit took place, on average $28 \pm 24$ days post-injury (range, 3 - 126). Mean length of sub-acute rehabilitation stay was $28 \pm 23$ days for all patients (range, 4 - 96). The average lengths of stay of patients with severe TBI were significantly longer both in acute and rehabilitation settings $(\mathrm{P}<0.001, \mathrm{P}=0.005)$. Among patients with moderate TBI, $100 \%$ were discharged to their homes. Among patients with severe TBI, 61\% were discharged to their homes, $27 \%$ to nursing homes and/or other care facilities, and $11 \%$ to other local rehabilitation facilities.

\section{Measurements of functional recovery}

Mean FIM scores at admission and discharge from sub-acute rehabilitation and at 12 months after injury in moderate and severe TBI patients are shown in Table 3. All mean FIM scores improved significantly from admission to 12 months in both groups. The total FIM score improved more in the severe than in the moderate TBI group (32 versus 14 points, $\mathrm{P}<0.001)$.

All mean FIM scores in both moderate and severe TBI groups improved significantly from admission to discharge from sub-acute rehabilitation. However, in the period between discharge from rehabilitation and 12 months after injury, there was no further improvement in any FIM score in the moderate TBI group. Severe TBI patients improved in FIM total and FIM-M, but not in FIM-COG.

Individual FIM scores in moderate and severe TBI patients are shown in Figure 1. The majority in both groups improved during the period from discharge from rehabilitation to 12 months follow-up, but three severe TBI patients were unchanged and two patients (one with severe and one with moderate $\mathrm{TBI}$ ) became more impaired due to secondary TBI complications during this period (Fig. 1). At 12 months follow-up, 95\% of moderate TBI patients had a FIM-score from 109 - 126 (functionally independent) one year after injury compared to $74 \%$ of those with severe TBI. The majority of moderate TBI patients reached full FIM-M sub-score $(86 \%)$, and three quarters of them reached full FIM-COG score. Twelve percent of the severe TBI patients had a score $<72$ one year after injury. 


\section{GOSE 12 months}

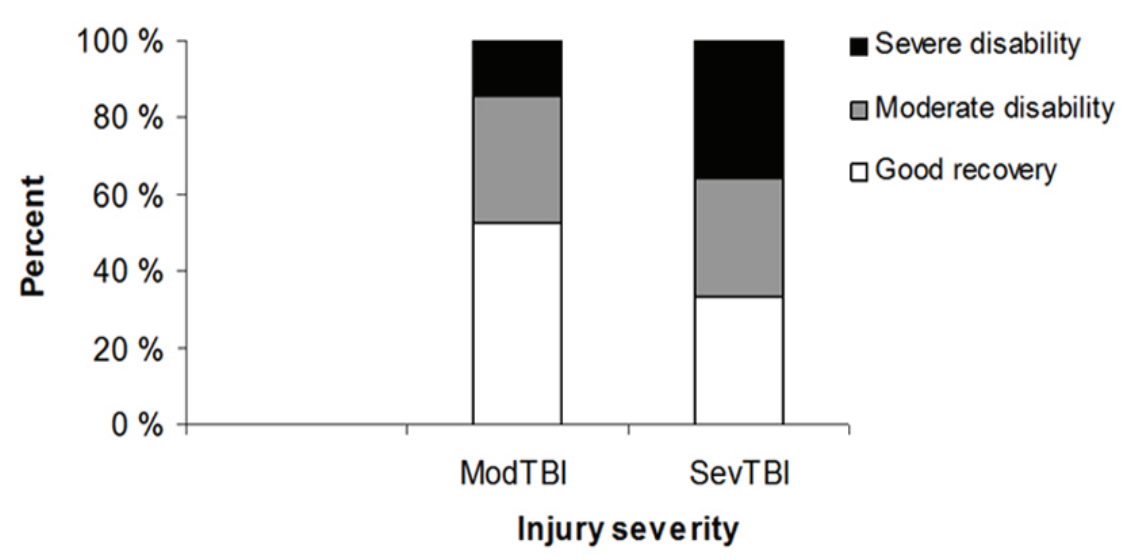

Figure 2. The distribution of GOSE outcome in moderate and severe TBI patients.

Functional global outcome for the whole group as assessed by GOSE at 12 months was "good recovery" in 40\%, "moderate disability" in 32\% and "severe disability" in $29 \%$. The distribution of GOSE outcome in moderate and severe TBI is shown in Figure 2. As expected the outcome distribution was significantly shifted towards better recovery and less severe disability in the moderate TBI group $(\mathrm{P}<0.05)$. The outcome was "good recovery" in $11 / 21$ (52\%) with moderate TBI versus 14/42 (33\%) in severe TBI, "moderate disability" in $7 / 21(33 \%)$ with moderate TBI versus $13 / 42$ $(31 \%)$ in severe TBI, and "severe disability" in $3 / 21(14 \%)$ with moderate TBI versus 15/42 (36\%) in severe TBI.

\section{Predictors of functional recovery (FIM total score) 12 months after injury}

The influence of factors entered into the final multiple regression analysis is shown in Table 2. We identified three variables that were significant predictors of FIM total scores 12 months after injury: GCS at admission to sub-acute rehabilitation, PTA duration, and LOS in the rehabilitation unit. The adjusted $\mathrm{R}$ square was 0.47 meaning that PTA duration, GCS admission rehabilitation and LOS rehab explained half of the FIM variance at 12 months. The B coefficient was positive for GCS at admission to rehabilitation and LOS rehab and negative for PTA, meaning that a higher GCS at admission, a shorter PTA, and a longer stay in the rehabilitation unit equated to better functional level 12 months after injury. GCS admission rehabilitation score had the largest influence $(\mathrm{B}=5.058)$, followed by LOS rehab $(\mathrm{B}=0.458)$, and PTA duration $(\mathrm{B}=-0.209)$.

\section{Discussion}

In this study, we have quantified the time course and magni- tude of recovery during the first year after TBI in a cohort of 63 patients with moderate $(\mathrm{N}=21)$ or severe $(\mathrm{N}=42)$ TBI.

The functional level, as assessed by mean FIM improved significantly during the first 12 months after injury. The greatest improvement was from admission to discharge in the sub-acute rehabilitation phase, on average two months after injury. It is expected from the natural course after TBI that most of the spontaneous recovery from injury happens initially [21]. Previous studies have documented by neuropsychological assessment that cognitive recovery after moderate and severe TBI is more rapid the first 5 months after injury and continues at a slower rate the next 7 months [22].

During the period from discharge from the rehabilitation clinic, to 12 months after injury, there was an improvement in mean FIM motor score in severe TBI but not in moderate TBI patients. Mean scores of cognitive function did not improve in any of the groups. The lack of statistically significant improvement in these mean FIM scores may in part be due to a low number of patients, since individual total scores improved in the majority of both moderate and severe TBI patients (Fig. 1). As reported in the literature, the FIM was developed to track progress in functional status during inpatient rehabilitation and has a ceiling effect at one-year post injury [23]. Lack of improvement in the later phase found in this study may also in part be due to the fact that FIM is not sensitive enough to detect changes in either upper functional level or light cognitive dysfunction [21].

Most previous studies on post-TBI prognosis focus on severe or mild TBI. Moderate TBI is less well studied, and many cases are probably never referred to rehabilitation hospitals. We have previously shown that a considerable portion of moderate TBI patients had significant residual disability, largely cognitive, at discharge from sub-acute rehabilitation hospital [4]. In this study we show that half of them had moderate or severe disability evaluated by GOSE 12 months after injury. The proportion of severe disability is in accor- 
dance with the study by Whitnal et al. (2006) [24]. However, in a recent Norwegian study on neuropsychological and functional recovery, no moderate TBI participant had severe disability at 12 months after TBI. This may be due to the fact that patients that were not able to be tested sub-acutely because of prolonged PTA were excluded [9].

The lack of significant improvements in cognitive function after discharge from sub-acute rehabilitation may reflect the limitations in measuring change in FIM-COG sub scores in later phase TBI. However, our results raise a question of whether more intensive rehabilitation than what we offered is needed during the post-acute phases after TBI. After discharge from sub-acute rehabilitation, our patients were offered standardized visits from our specialized brain injury rehabilitation team at three months post-discharge and 12 months post-injury. In addition, the majority of our patients were offered visits, telephone contact, assistance and education by the interdisciplinary team at home or in other institutional settings when considered necessary. It is a question whether a more intensive specialized rehabilitation program could have resulted in greater functional recovery at 12 months.

We have recently shown that longer stays in the rehabilitation unit, a short PTA period and a high GCS score at admission to rehabilitation are positive predictors of functional recovery at discharge from sub-acute rehabilitation [4]. This study shows that the same factors are predictors of functional outcome at 12 months after injury. GCS at admission to rehabilitation turned out to be the strongest predictor $(\mathrm{B}=5.058)$. This may implicate that GCS score at admission to rehabilitation is a strong predictor of outcome after TBI, in addition to PTA which has been reported as the strongest predictor in other studies $[1,3]$.

The GCS is the most widely used clinical measurement of TBI severity [25]. GCS scores in the acute phase provide guidance for early care and prediction of early outcome such as mortality and morbidity [25-29]. GCS is also used in predicting late global outcome such as functional level and return to employment $[31,32]$. There is controversy about which GCS score should be recorded since interventions in the early medical management of moderate and severe TBI, may complicate GCS assessment and provide inaccurate prognostic predictions for some patients [25, 32].

PTA is the interval from injury to return of orientation or continuous memory [3]. In our regression analysis PTA duration turned out to be a weak predictor of functional level $(B=-0.209)$ at 12 months after injury. In contrast to this, others have found PTA duration to be the strongest predictor of functional outcome, and more predictive than GCS at rehabilitation admission [33-35]. Still, its predicative accuracy and clinical utility are limited by the large outcome variability [2, 34, 36-40]. In a study of Sherer et al. (2008), two PTA durations of 4 and 8 weeks emerged as global outcome threshold points that should aid prognosis accuracy after TBI
[3].

A longer stay in the rehabilitation unit was associated with a better functional level one year after injury $(\mathrm{B}=$ 0.458). This agrees with a report from Cowen et al. (1995) who found that longer inpatient rehabilitation (LOS) was associated with significantly higher gains in both FIM-M and FIM-COG scores [41]. A logical circular argument may be that longer stays are also associated with a more serious injury and a lower starting point. The regression model should ideally correct for this and show the role of LOS as an independent predictor of functional level. Overall, a longer stay may increase the spontaneous recovery magnitude [4].

GOSE is often considered to be a better assessment on long-term global function after TBI than FIM as the GOSE measures impairments, activity limitations and participation restrictions while the FIM measures activity limitations in motor and self-care skills. In agreement with this, our results showed some discrepancy between functional level as assessed by GOSE and FIM at 12 months, especially in the group with moderate TBI. By using GOSE we found that $47 \%$ of our moderate TBI patients were still moderately or severely disabled at 12 months, whereas FIM detected reduced cognitive scores in only $24 \%$ and motor scores in $14 \%$. Further, $95 \%$ of moderate TBI patients had a mean FIM total score indicating functional independence, while only $52 \%$ of the moderates achieved good recovery as assessed by GOSE at 12 months.

We think it is important to look at the moderately injured as one group and not combined groups of mild-moderate or moderate-severe. For the moderately injured most reports are made in the 1980s, and outcome was often determined at 3 and 6 months after injury. Follow-up studies beyond that period are lacking [42]. Also, commonly used outcome scales fail to measure outcome in mild and moderate TBI as they assess functional disability more than cognitive deficits [42]. Our results may however support those studies which demonstrate that although neuropsychological impairment at baseline usually resolves within three months, moderately injured may still have selective cognitive deficits (attention and memory) one year after injury [9, 18, 42, 43]. Finally, no agreement has been made on the predictive value of the GCS score and the PTA duration on outcome among moderately injured [44].

One limitation of this study was the small sample size. However, a strength was the few drop-outs. Another limitation may be the ceiling effect experienced when measuring cognitive function with FIM. Neuropsychological tests would have been preferable for a better description of cognitive functional recovery after TBI. One should be careful in generalizing our results with the overall TBI population as our cohort was limited to those considered as in need of specialized TBI rehabilitation. Many with moderate TBI are probably discharged from the acute hospital directly to their homes because they do not report TBI related problems in 
need of further follow-up.

\section{Conclusion}

Functional recovery (FIM) improved during the first year after moderate and severe TBI. The greatest improvement was in the sub-acute phase during the stay in a specialized rehabilitation unit. There was no improvement in cognitive function after discharge from sub-acute rehabilitation as evaluated by mean FIM scores, and only the severe TBI group improved their motor function. Residual disability was reported in $47 \%$ of moderate TBI patients as measured by GOSE at 12 months post injury indicating the importance of follow-up and rehabilitation for these patients. Longer stays at the rehabilitation unit, a short PTA period and a high GCS score at admission to rehabilitation were positive predictors of functional level (FIM) at 12 months follow-up. Our results may suggest a need for more intense cognitive training and rehabilitation overall in the post-acute TBI phase. The results may help guidance in planning, research, treatment, and decision making of required services for outpatient rehabilitation after TBI.

\section{Acknowledgement}

We would like to thank statistician Are Hugo Pripp at Oslo University Hospital, for his supervision in statistics, neuropsychologist Eli Torland for performing GOAT tests on our patients, ward leader Lars-Otto Nome and physiatrist Rein Knoph and their team colleagues at Clinic for Rehabilitation, Sorlandet Hospital, Kristiansand, for co-operation and data collection.

\section{Disclosures}

This study has been financed with the aid of EXTRA funds from the Norwegian Foundation for Health and Rehabilitation. No previous presentation of the research, manuscript, or abstract exists.

\section{References}

1. Walker WC, Ketchum JM, Marwitz JH, Chen T, Hammond F, Sherer M, Meythaler J. A multicentre study on the clinical utility of post-traumatic amnesia duration in predicting global outcome after moderate-severe traumatic brain injury. J Neurol Neurosurg Psychiatry 2010;81(1):87-89.

2. Brown AW, Malec JF, McClelland RL, Diehl NN, Englander J, Cifu DX. Clinical elements that predict outcome after traumatic brain injury: a prospective multi- center recursive partitioning (decision-tree) analysis. J Neurotrauma 2005;22(10):1040-1051.

3. Sherer M, Struchen MA, Yablon SA, Wang Y, Nick TG. Comparison of indices of traumatic brain injury severity: Glasgow Coma Scale, length of coma and post-traumatic amnesia. J Neurol Neurosurg Psychiatry 2008;79(6):678-685.

4. Sandhaug M, Andelic N, Vatne A, Seiler S, Mygland A. Functional level during sub-acute rehabilitation after traumatic brain injury: course and predictors of outcome. Brain Inj 2010;24(5):740-747.

5. Sorbo AK, Blomqvist M, Emanuelsson IM, Rydenhag B. Psychosocial adjustment and life satisfaction until 5 years after severe brain damage. Int $\mathrm{J}$ Rehabil Res 2009;32(2):139-147.

6. Sidaros A, Skimminge A, Liptrot MG, Sidaros K, Engberg AW, Herning M, Paulson OB, et al. Long-term global and regional brain volume changes following severe traumatic brain injury: a longitudinal study with clinical correlates. Neuroimage 2009;44(1):1-8.

7. Engberg AW, Teasdale TW. Psychosocial outcome following traumatic brain injury in adults: a long-term population-based follow-up. Brain Inj 2004;18(6):533-545.

8. Andelic N, Sigurdardottir S, Schanke AK, Sandvik L, Sveen U, Roe C. Disability, physical health and mental health 1 year after traumatic brain injury. Disabil Rehabil 2010;32(13):1122-1131.

9. Sigurdardottir S, Andelic N, Roe C, Schanke AK. Cognitive recovery and predictors of functional outcome 1 year after traumatic brain injury. J Int Neuropsychol Soc 2009;15(5):740-750.

10. Bilbao A, Kennedy C, Chatterji S, Ustun B, Barquero JL, Barth JT. The ICF: Applications of the WHO model of functioning, disability and health to brain injury rehabilitation. NeuroRehabilitation 2003;18(3):239-250.

11. Ruff RM, Iverson GL, Barth JT, Bush SS, Broshek DK. Recommendations for diagnosing a mild traumatic brain injury: a National Academy of Neuropsychology education paper. Arch Clin Neuropsychol 2009;24(1):3-10.

12. Lehtonen S, Stringer AY, Millis S, Boake C, Englander J, Hart T, High W, et al. Neuropsychological outcome and community re-integration following traumatic brain injury: the impact of frontal and non-frontal lesions. Brain Inj 2005;19(4):239-256.

13. Levin HS, O'Donnell VM, Grossman RG. The Galveston Orientation and Amnesia Test. A practical scale to assess cognition after head injury. J Nerv Ment Dis 1979;167(11):675-684.

14. Grimby G, Gudjonsson G, Rodhe M, Sunnerhagen KS, Sundh V, Ostensson ML. The functional independence measure in Sweden: experience for outcome measurement in rehabilitation medicine. Scand J Rehabil Med 1996;28(2):51-62.

15. Granger CV, Hamilton BB, Linacre JM, Heinemann 
AW, Wright BD. Performance profiles of the functional independence measure. Am J Phys Med Rehabil 1993;72(2):84-89.

16. Corrigan JD, Smith-Knapp K, Granger CV. Validity of the functional independence measure for persons with traumatic brain injury. Arch Phys Med Rehabil 1997;78(8):828-834.

17. Deutsch A, Granger CV, Heinemann AW, Fiedler RC, DeJong G, Kane RL, Ottenbacher KJ, et al. Poststroke rehabilitation: outcomes and reimbursement of inpatient rehabilitation facilities and subacute rehabilitation programs. Stroke 2006;37(6):1477-1482.

18. Wilson JT, Pettigrew LE, Teasdale GM. Structured interviews for the Glasgow Outcome Scale and the extended Glasgow Outcome Scale: guidelines for their use. J Neurotrauma 1998;15(8):573-585.

19. van der Naalt J, van Zomeren AH, Sluiter WJ, Minderhoud JM. One year outcome in mild to moderate head injury: the predictive value of acute injury characteristics related to complaints and return to work. J Neurol Neurosurg Psychiatry 1999;66(2):207-213.

20. Heinemann AW, Linacre JM, Wright BD, Hamilton BB, Granger C. Relationships between impairment and physical disability as measured by the functional independence measure. Arch Phys Med Rehabil 1993;74(6):566-573.

21. Kunik CL, Flowers L, Kazanjian T. Time to rehabilitation admission and associated outcomes for patients with traumatic brain injury. Arch Phys Med Rehabil 2006;87(12):1590-1596.

22. Christensen BK, Colella B, Inness E, Hebert D, Monette G, Bayley M, Green RE. Recovery of cognitive function after traumatic brain injury: a multilevel modeling analysis of Canadian outcomes. Arch Phys Med Rehabil 2008;89(12 Suppl):S3-15.

23. Cohen ME, Marino RJ. The tools of disability outcomes research functional status measures. Arch Phys Med Rehabil 2000;81(12 Suppl 2):S21-29.

24. Whitnall L, McMillan TM, Murray GD, Teasdale GM. Disability in young people and adults after head injury: 5-7 year follow up of a prospective cohort study. J Neurol Neurosurg Psychiatry 2006;77(5):640-645.

25. The Brain Trauma Foundation. The American Association of Neurological Surgeons. The Joint Section on Neurotrauma and Critical Care. Glasgow coma scale score. J Neurotrauma 2000;17(6-7):563-571.

26. Bahloul M, Chelly H, Ben Hmida M, Ben Hamida C, Ksibi H, Kallel H, Chaari A, et al. Prognosis of traumatic head injury in South Tunisia: a multivariate analysis of 437 cases. J Trauma 2004;57(2):255-261.

27. Murray GD, Teasdale GM, Braakman R, Cohadon F, Dearden M, Iannotti F, Karimi A, et al. The European Brain Injury Consortium survey of head injuries. Acta Neurochir (Wien) 1999;141(3):223-236.
28. Rovlias A, Kotsou S. Classification and regression tree for prediction of outcome after severe head injury using simple clinical and laboratory variables. J Neurotrauma 2004;21(7):886-893.

29. Signorini DF, Andrews PJ, Jones PA, Wardlaw JM, Miller JD. Predicting survival using simple clinical variables: a case study in traumatic brain injury. J Neurol Neurosurg Psychiatry 1999;66(1):20-25.

30. Cifu DX, Keyser-Marcus L, Lopez E, Wehman P, Kreutzer JS, Englander J, High W. Acute predictors of successful return to work 1 year after traumatic brain injury: a multicenter analysis. Arch Phys Med Rehabil 1997;78(2):125-131.

31. Dikmen SS, Ross BL, Machamer JE, Temkin NR. One year psychosocial outcome in head injury. J Int Neuropsychol Soc 1995;1(1):67-77.

32. Stocchetti N, Pagan F, Calappi E, Canavesi K, Beretta L, Citerio G, Cormio M, et al. Inaccurate early assessment of neurological severity in head injury. J Neurotrauma 2004;21(9):1131-1140.

33. Ariza M, Mataro M, Poca MA, Junque C, Garnacho A, Amoros S, Sahuquillo J. Influence of extraneurological insults on ventricular enlargement and neuropsychological functioning after moderate and severe traumatic brain injury. J Neurotrauma 2004;21(7):864-876.

34. Katz DI, Alexander MP. Traumatic brain injury. Predicting course of recovery and outcome for patients admitted to rehabilitation. Arch Neurol 1994;51(7):661-670.

35. Sherer M, Sander AM, Nick TG, High WM, Jr., Malec JF, Rosenthal M. Early cognitive status and productivity outcome after traumatic brain injury: findings from the TBI model systems. Arch Phys Med Rehabil 2002;83(2):183-192.

36. Bishara SN, Partridge FM, Godfrey HP, Knight RG. Post-traumatic amnesia and Glasgow Coma Scale related to outcome in survivors in a consecutive series of patients with severe closed-head injury. Brain Inj 1992;6(4):373-380.

37. Ellenberg JH, Levin HS, Saydjari C. Posttraumatic Amnesia as a predictor of outcome after severe closed head injury. Prospective assessment. Arch Neurol 1996;53(8):782-791.

38. Asikainen I, Kaste M, Sarna S. Predicting late outcome for patients with traumatic brain injury referred to a rehabilitation programme: a study of 508 Finnish patients 5 years or more after injury. Brain Inj 1998;12(2):95107.

39. Hellawell DJ, Taylor RT, Pentland B. Cognitive and psychosocial outcome following moderate or severe traumatic brain injury. Brain Inj 1999;13(7):489-504.

40. Balestreri M, Czosnyka M, Chatfield DA, Steiner LA, Schmidt EA, Smielewski P, Matta B, et al. Predictive value of Glasgow Coma Scale after brain trauma: change in trend over the past ten years. J Neurol Neurosurg Psy- 
chiatry 2004;75(1):161-162.

41. Cowen TD, Meythaler JM, DeVivo MJ, Ivie CS, 3rd, Lebow J, Novack TA. Influence of early variables in traumatic brain injury on functional independence measure scores and rehabilitation length of stay and charges. Arch Phys Med Rehabil 1995;76(9):797-803.

42. Hugenholtz H, Stuss DT, Stethem LL, Richard MT. How long does it take to recover from a mild concussion? Neurosurgery 1988;22(5):853-858.

43. Dikmen S, McLean A, Temkin N. Neuropsychological and psychosocial consequences of minor head injury. J Neurol Neurosurg Psychiatry 1986;49(11):1227-1232.

44. Kibby MY, Long CJ. Minor head injury: attempts at clarifying the confusion. Brain Inj 1996;10(3):159-186. 